Abstract 134 Table 1 Establishment of the LUPHAS scoring system

\begin{tabular}{|c|c|c|}
\hline & Predictors & Points \\
\hline \multirow[t]{3}{*}{$\mathbf{L}$} & Lymphocyte count & \\
\hline & $\geq 800 /$ ul & 1 \\
\hline & $<800 /$ ul & 4 \\
\hline \multirow[t]{3}{*}{ U } & Urea & \\
\hline & $\leq 7.6 \mathrm{mmol} / \mathrm{L}$ & 1 \\
\hline & $>7.6 \mathrm{mmol} / \mathrm{L}$ & 4 \\
\hline \multirow[t]{3}{*}{$\mathbf{P}$} & Maximum Prednisone dose in the past & \\
\hline & $<60 \mathrm{mg} / \mathrm{d}$ & 1 \\
\hline & $\geq 60 \mathrm{mg} / \mathrm{d}$ & 5 \\
\hline \multirow[t]{3}{*}{ H } & History of Hydroxychloroquine use & \\
\hline & Yes & -1 \\
\hline & No & 0 \\
\hline \multirow[t]{5}{*}{ A } & Age, $y$ & \\
\hline & $\leq 20$ & 1 \\
\hline & $21-40$ & 2 \\
\hline & $41-60$ & 3 \\
\hline & $>60$ & 4 \\
\hline \multirow[t]{4}{*}{$\mathbf{S}$} & qSOFA score & \\
\hline & 0 & 0 \\
\hline & 1 & 3 \\
\hline & $\geq 2$ & 6 \\
\hline
\end{tabular}

mortality was recorded, underlining that special attention should be paid to these patients. Several independent predictors for all-cause mortality were successfully identified in our study. The real-world evidence-based LUPHAS score might be a promising tool for risk stratification in clinical practice.

Funding Source(s): None

\section{INFLUENCE OF GENETIC VARIANTS ON AVASCULAR NECROSIS IN PATIENTS WITH SYSTEMIC LUPUS ERYTHEMATOSUS}

${ }^{1}$ So-Young Bang*, ${ }^{2}$ Youngho Park, ${ }^{1}$ Hyuk-Hee Kwon, ${ }^{3}$ Kwangwoo Kim, ${ }^{1}$ Hye-Soon Lee, 'Sang-Cheol Bae. 'Department of Rheumatology, Hanyang University Hospital for Rheumatic Diseases; ${ }^{2}$ Clinical Research Center for Rheumatoid Arthritis; ${ }^{3}$ Department of Biology, Kyung Hee University, Republic of Korea

10.1136/lupus-2019-Ism. 135

Background Avascular necrosis (AVN) incompletely understood genetic architecture in patients with systemic lupus erythematosus (SLE). The aims of this study were to investigate genetic risk factors, biological and functional pathways associated with the risk of AVN in a large SLE cohort in Korea.

Methods Patients with SLE were enrolled in the Hanyang BAE Lupus cohort, in whom damage was measured annually according to the Systemic Lupus International Collaborating Clinics/American College of Rheumatology Damage Index (SDI). We conducted an association study to determine genetic risk factors for AVN in 612 SLE cases that genotyped by high-density immune-loci genotyping array (Immunochip) and genome-wide association study (GWAS) using Illumina HumanOmni1-Quad array.

Results Symptomatic AVN was the most common type of musculoskeletal damage $(14.2 \%, \mathrm{n}=87)$ among 612 SLE patients in Korea. In analysis of clinical factors, use of a high cumulative corticosteroid dose (OR 3.62, $\mathrm{p}=0.015$ ) significantly increased the risk of $\mathrm{AVN}$ in multivariable analysis. We found the top 10 single-nucleotide polymorphisms (SNPs) associated with AVN $(p<5.0 \times 106)$ in SLE patients with AVN after 
adjusting for age, sex, disease duration, total cumulative corticosteroid dose, and top 10 PCs as covariates. In further analysis of SLE patients with AVN compared with SLE patients without AVN treated by a high corticosteroid [cumulative dose $>20 \mathrm{~g}$, the AVN-risk loci were highly expressed in fibroblasts $(p=8.78 \times 105)$ and musculoskeletal system $(\mathrm{p}=1.13 \times 104)$ using DEPICT.

Conclusions These findings provide genetic evidence that pathway of fibroblasts are relevant to osteonecrosis. Individual genetic risk for the development of AVN should be assessed prior to treatment for SLE.

Funding Source(s): None

\section{INFLUENCE OF GENETIC RISK VARIANTS ON THE CLINICAL SUBPHENOTYPES OF SYSTEMIC LUPUS ERYTHEMATOSUS IN A KOREAN COHORT}

${ }^{1}$ Hyuk-Hee Kwon, ${ }^{2}$ Eunji Ha, ${ }^{1}$ So-Young Bang*, ${ }^{1}$ Hye-Soon Lee, ${ }^{2}$ Kwangwoo Kim, ${ }^{1}$ SangCheol Bae. 'Department of Rheumatology, Hanyang University Hospital for Rheumatic Diseases; ${ }^{2}$ Department of Biology, Kyung Hee University, Republic of Korea

\subsection{6/lupus-2019-Ism.136}

Background Systemic lupus erythematosus (SLE) is a multifactorial autoimmune disease with diverse heterogeneous phenotypes. Impact of complex genetic variants on the clinical manifestations of SLE was not fully understood. The aim of this study is to identify the cumulative effect of SLE-risk variants on clinical manifestations and autoantibody profiles in patients with SLE.

Methods A total of 781 Korean patients from the Hanyang BAE lupus cohort were genotyped by Immunochip and genome-wide association study (GWAS) using Illumina HumanOmni1-Quad array. Weighted genetic risk score (GRS) were calculated from 45 well-validated non-HLA SNPs and HLA SLE-risk loci. Individual GRS was tested for associations with the clinical subphenotypes based on 1997 ACR criteria of SLE and the development of autoantibody by using a linear regression or a logistic regression adjusting for the top 10 PCs as covariates, respectively.
Results We identified weighted GRS calculated from non-HLA and HLA SLE-risk loci with significant associations in various SLE subphenotypes defined by the ACR criteria (mean number 5.74) among 11 criteria. Individuals weighted GRS showed significantly positive correlation with the number of ACR criteria in a linear regression model (coefficient $=0.128$, $\mathrm{p}=9.00 \times 103)$. Consistently, a significant positive correlation with the number of ACR in both non-HLA GRS (coefficient $=0.110, p=0.027$ ) and HLA GRS (coefficient=0.06, $\mathrm{p}=0.021)$ was observed, respectively.

In a clinical subphenotype analysis, weighted GRS from non-HLA and HLA risk loci were significantly related to malar rash $(\mathrm{OR} 1.23, \mathrm{p}=2.68 \times 103)$, renal disorder $(\mathrm{OR} 1.15$, $\mathrm{p}=4.41 \times 102)$, and thrombocytopenia (OR 1.21, $\mathrm{p}=7.55 \times 103$ ) using a multivariable logistic regression. Weighted GRS were strongly associated with production of anti-DNA antibody (OR 1.38, p=2.18 $\times 103$ ).

Conclusions In conclusion, a high cumulative SLE-risk effect promoted diverse clinical manifestations and influenced the production of auto-antibodies including anti-DNA, that could provide clues to identifying distinctive mechanisms in SLE.

Funding Source(s): None

\section{MYOCARDITIS IN PEDIATRIC LUPUS: A CLINICAL CONUNDRUM}

${ }^{1}$ Nameirakpam Johnson*, ${ }^{2}$ Deepti Suri, ${ }^{3}$ Anju Gupta, ${ }^{3}$ Amit Rawat, ${ }^{2}$ Surjit Singh. ${ }^{1}$ Dept. of Pediatrics, Allergy- Immunology Unit, Postgraduate Institute of Medical Education and Research; ${ }^{2}$ Postgraduate Institute of Medical Education and Research, Chandigarh, India; ${ }^{3}$ PGIMER Chandigarh

\subsection{6/lupus-2019-Ism. 137}

Background Myocarditis in pediatric lupus is uncommon but carry a significant morbidity and mortality.

Methods We reviewed our cohort of children with lupus registered between January 1993 to November 2018. Of the 140 lupus patients that were diagnosed during this time, 4 had myocarditis.

Abstract 137 Table 1 Laboratory Investigations

\begin{tabular}{|c|c|c|c|c|}
\hline Investigation & Case 1 & Case 2 & Case 3 & Case 4 \\
\hline Haemoglobin $(g / L)$ & $94 \mathrm{~g} / \mathrm{L}$ & $92 \mathrm{~g} / \mathrm{L}$ & $80 \mathrm{~g} / \mathrm{L}$ & $69 \mathrm{~g} / \mathrm{L}$ \\
\hline White cell counts & $6.7 \times 10^{9} / \mathrm{L}$ & $7.2 \times 10^{9} / \mathrm{L}$ & $6.5 \times 10^{9} / \mathrm{L}$ & $6.4 \times 10^{9} / \mathrm{L}$ \\
\hline Lymphocyte count & $1.15 \times 10^{9} / \mathrm{L}$ & $1.91 \times 10^{9} / \mathrm{L}$ & $1.65 \times 10^{9} / \mathrm{L}$ & $1.25 \times 10^{9} / \mathrm{L}$ \\
\hline Platelets & $130 \times 10^{9} / \mathrm{L}$ & $150 \times 10^{9} / \mathrm{L}$ & $220 \times 10^{9} / \mathrm{L}$ & $90 \times 10^{9} / \mathrm{L}$ \\
\hline Urine routine & No $R B C$, & No $R B C$, & No $\mathrm{RBC}$, & Plenty RBCs, 3+albumin \\
\hline Urine protein $\left(\mathrm{mg} / \mathrm{m}^{2} /\right.$ hour $)$ & No albumin & No albumin & No albumin & $82 \mathrm{mg} / \mathrm{m}^{2} /$ hour \\
\hline C3 (Normal 50-150 mg/dL) & $27 \mathrm{mg} / \mathrm{dl}$ & $28 \mathrm{mg} / \mathrm{dL}$ & $31 \mathrm{mg} / \mathrm{dl}$ & $21 \mathrm{mg} / \mathrm{dl}$ \\
\hline C4 (Normal 20-50 mg/dL) & $4 \mathrm{mg} / \mathrm{dl}$ & $3 \mathrm{mg} / \mathrm{dL}$ & $10 \mathrm{mg} / \mathrm{dl}$ & $3 \mathrm{mg} / \mathrm{dl}$ \\
\hline ANA & 4+diffuse & 3+diffuse & 3+diffuse & 4+diffuse \\
\hline Anti dsDNA (N:<25 IU/mL) & 59 & 583 & 112 & 346 \\
\hline Antiphospholipid antibodies: & Positive & Negative & Negative & Negative \\
\hline a) Lupus anticoagulant & Negative & Negative & Negative & Negative \\
\hline $\begin{array}{l}\text { b) Anticardiolipin antibody (IgG and } \lg M \text { ) c) Anti B2 } \\
\text { Glycoprotein }-1 \text { antibody (IgG and } \lg M \text { ) }\end{array}$ & Negative & Negative & Negative & Negative \\
\hline 2Dimensional Echocardiography & $\begin{array}{l}\text { Mild pericardial effusion, } \\
\text { dilated left ventricle, ejection } \\
\text { fraction (EF) } 30 \%\end{array}$ & $\begin{array}{l}\text { Mild pericardial } \\
\text { effusion, EF } 25 \%\end{array}$ & $\begin{array}{l}\text { Mild pericardial effusion, } \\
\text { moderate mitral regurgitation, } \\
\text { mild tricuspid regurgitation, global } \\
\text { hypokinesia, EF } 56 \%\end{array}$ & $\begin{array}{l}\text { Moderate mitral regurgitation, } \\
\text { mild tricuspid regurgitation, global } \\
\text { hypokinesia, EF } 18 \%\end{array}$ \\
\hline
\end{tabular}

